\title{
Is There a Future for Depression Digital Motion Constructs in Psychiatry?
}

\author{
NORMAN ALESSI, M.D.
}

\begin{abstract}
Psychomotor retardation has been recognized as a principal component of depression for centuries. Amongst symptoms and signs associated with depression, it is seen as having high predictive validity, correlating with severity of illness and the outcome of numerous therapeutic interventions. Of the two components-"psycho" and "motor" — the psychological component has received the most thorough investigation and has been given the greatest consideration. The "motor" (or motion) component has been given little consideration. A review of the literature suggests few studies have attempted to quantitatively characterize this phenomenon or use it as anything more than one indice among other signs and symptoms of depression. Unlike other phenomena associated with depression, the use of motion alterations has lagged in significance due to limited technology that would allow its study; depression has been seen predominantly as a "mood" disorder, with principal interest being in the "feelings" associated with the disorder. Recent advances in motion capture technologies allow motion alterations to be used for many purposes, both quantitative and qualitative. These sources of information appear to have direct and indirect impact. There is a fertile future for motion capture constructs in the study of depression, and recent technological advances will allow progress to occur in this area.
\end{abstract}

\section{INTRODUCTION}

$\mathbf{T}$ HE PRINCIPAL CHARACTERISTICS of depression have been known for a number of centuries. ${ }^{1-3}$ Foremost amongst the symptoms has been psychomotor alterations, particularly evidenced by slowing during an episode and a return to normal after a resolution of the episode. Psychomotor slowing has been shown to correlate with the degree of depression and the onset of depression. ${ }^{4-6,17}$ Psychomotor slowing has also been found to occur with greater frequency with various subtypes: bipolar versus unipolar; endogenous versus nonen- dogenous; psychotic versus nonpsychotic; and vascular versus nonvascular. ${ }^{9-13}$ Also, response to therapeutic interventions, including electroconvulsive therapy, has been correlated with motor slowing. ${ }^{14}$ Some have postulated, given the significance of the motor slowing, that depressive illnesses are in fact movement disorders, not mood disorders. ${ }^{15,16}$

Compared to other symptoms and signs associated with depression, psychomotor alterations have not received extensive study or attention. Symptoms most frequently studied have been alterations in sleep, cognition, appetite, and sexual desire. In large part, psy- 
chomotor retardation research has primarily focused on the cognitive alterations associated with depression, i.e., decreased concentration, forgetfulness, and indecisiveness. The motor component has rarely been dealt with. An exception has been the work of Parker and colleagues, who have pursued psychomotor alterations and have developed a methodology to understand the significance of motor alterations. They have developed an observationbased instrument (CORE) that codifies the presence of psychomotor alterations amongst depressed patients. ${ }^{17-20}$ CORE enables one to measure the severity of psychomotor phenomena in patients and to arrange types of motor alterations into three groups: retardation, agitation, or noninteractiveness. Using CORE, they have been able to predict response to treatment intervention and treatment outcome. ${ }^{21}$ Certainly Parker's work adds to the validity of the significance of motor alterations in depression and the justification for more aggressive research to determine its relevance.

\section{PREVIOUS APPLIED MOTION TECHNOLOGY STUDIES}

Given the significance of motor alterations in depression, one would expect that there would have been more studies with this as a primary focus. In fact, there are few. Certainly, those utilizing technologies to reflect motion alterations have been limited. In part, this may be explained on the basis of limited technologies that would allow a more quantitative or qualitative characterization of motor alterations. Studies that have attempted to characterize motor slowing have employed facial electromyograms, speech pause time, gross motor analysis, and gait analysis. ${ }^{21-29}$ All these techniques revealed that the motor component of psychomotor retardation could be characterized and did differentiate depressed from normal subjects, yet the studies have been rarely cited. One would have to assume that either motor alterations have little significance or the technologies used provide little additional insight than one could gain through observation. If that is the case, which might be true in the instances mentioned, then one could understand why little research has occurred in this area. Others have expressed an interest in the lack of progress in this area and emphasized its importance for future research. ${ }^{53}$

Currently, there does not exist a frame of reference for discourse concerning the use of motion technologies. When the topic arises, the most frequently asked questions are: Can't the same data be derived from clinical observations? Aren't our current rating scales sufficient? Couldn't video be used, and wouldn't it serve the same purpose? What can be gained by using motion capture technology? These are reasonable questions. In fact, it is unclear what might have been gained using older technologies, the advent of digital motion capture technologies appears to bode well for future applications in psychiatry.

\section{DIGITAL MOTION CAPTURE TECHNOLOGY}

Motion capture technology is not new. The first attempts to capture motion took place in the late 19 th century. This was at a time when "motion pictures" were being invented, and there was interest as to how best create them and determine what they might show. Muybridge was a leader in this field. ${ }^{31} \mathrm{He}$ used multiple cameras that took a sequence of photos as an object moved to trip the shutter of an array of cameras. These images were then shown in such a way as to create motion. Digital motion capture technology, in some ways, is very similar to these early attempts at capturing motion. Digital motion technology allows the acquisition of information about an object moving in space at rates of $60 \mathrm{~Hz}$ per second, if not faster. If a number of sensors / reflectors are placed on a complex object such as the human form or face, then information can be acquired about that complex object moving in space and time. Fundamentally, it is faster and more accurate, and allows the data to be used in ways that previously had not been imagined, given that it can be used to create objects in three-dimensional space.

One of the foremost properties of digital data is its accuracy. Given that motion capture technology systems can capture data at a rate of 60 
$\mathrm{Hz}$ per second from 36 sensors with an accuracy of $1 \mathrm{~mm}$, the collected data is more accurate than any data that can be captured by humans using any other means. This information can serve both for quantitative analytic purposes and qualitative purposes in the construction of animated figures, avatars, or interactive virtual humans.

To date, motion capture data has found its greatest applications in the areas of biomechanics, simulated digital virtual humans in design, and animation. ${ }^{30,40}$ Such utilization of data has never occurred in psychiatry despite the vast amount of research data supporting the notion that major alterations in motion occur involving the body and the face as core symptoms and signs in disorders such as depression, mania, and schizophrenia. Authors have speculated as to the potential of this technology, yet there continue to be no applications in psychiatry. ${ }^{54,47}$

\section{DIGITAL MOTION CAPTURE TECHNOLOGY REFRAMES POTENTIAL OF MOTION TECHNOLOGIES}

Offered here is a view of the potential of digital motion capture technology addressing the previously stated questions.

\section{Can't the same data be derived from observation?}

For some, the most fundamental question is, "Does motion capture technology offer any data that is not already being provided via a standard clinical session?" This question contains two elements: (1) Aren't our observations accurate enough? (2) Aren't our methods of documentation accurate enough? In fact, our current diagnostic system is heavily dependent on "subjective clinical observations," which have not been standardized. These observations are recorded in such a manner that they provide the minimal amount of data about a clinical situation. It is not clear that this data is enough.

\section{Aren't our current rating scales sufficient?}

Clinicians rarely use rating scales during the treatment of depression. Issues such as sever- ity lack operational definitions that are accepted and uniformly applied in the care of patients. True there are standardized diagnostic criteria for major mood disorders. Nevertheless, it is not clear that these criteria are followed rigorously, in the making of the diagnosis, in the documentation of the presence or absence of signs and symptoms of depression, or in the selection of therapeutic interventions. This may have as much to do with the weakness of the conceptual construct underlying these definitions as with the lack of applied rigor in the delivery of clinical care to these patients. Nevertheless, the fact that rating scales are not widely used suggests the limited utility of these instruments.

How might a digital motion capture system augment a clinician's encounter with a patient? When clinicians first meet a patient, often they are struck by the patient's affect and movement. This is before a single word is spoken. Yet, it is often enough time for a skilled clinician to begin the development of a differential diagnosis and to determine therapeutic planning. This can happen within seconds of when a patient enters a clinician's office. A digital motion capture system has the potential to capture the same data, similarly within seconds, and objectively record this data for future use. No clinician, no human has that potential. Humans do a wonderful job of recognizing a pattern that is presented to them, but they have limited capabilities in disaggregating that pattern at the level that a digital motion system would allow. Further, humans have fallible memory. How many clinicians can recall with accuracy their first encounter with a depressed patient 10 years ago, 5 years ago, 1 year ago, or even 1 month ago? A digital motion capture system does not forget, nor does it alter the data it captures.

Digital motion capture technology could open a doorway to data that is objective much as an electrocardiogram or other clinical laboratory tests do. Certainly, the quest for an objective clinical marker of depression has been the goal for many years of countless clinical researchers. These researchers have primarily looked to biochemical, endocrinological, and neurobiological phenomena as potential clinical markers. To date, there is no proven clini- 
cal "state" marker that is used by clinicians to characterize depression. The primary reason that no marker is used is because there is a lack of robust correlation to provide clinicians with certainty in its application. Digital motion capture data could prove more robust, and since it is not a biomarker, dependent on an alteration of a presumed pathophysiological perturbation, it would likely provide a more valid reflection of the disease state itself. Digital motion capture data would also prove to be highly accurate, and, since it can be recorded in digital form, it can be used for future analytic comparisons. Therefore, the more robust, valid, accurate, and storable digital motion capture data could ultimately be more valuable than clinical observation alone.

Couldn't video be used, and wouldn't it serve the same purpose?

Video offers both advantages and disadvantages as compared to digital motion capture. They both make recordings that, in principle, are more accurate than human observations alone, and both these recordings can be stored for future reference. Video has the advantages of being relatively inexpensive and widely available, though price and availability would undoubtedly change if the market for digital motion technologies grew. Digital motion technology has the advantages of providing a database that can be reused for a number of different purposes. Quantitatively, the data can be used in a number different analytic situations. No such type of data results from a video recording. Qualitatively, the data can be used to reconstruct virtual humans that would appear similar to the patient or, if so desired, as another individual. Certainly, a video recording could never serve this purpose. Video produces a two-dimensional representation of the phenomena that it is recording or broadcasting. Digital motion technology can be used to produce three-dimensional objects as well as twodimensional objects. Tele-immersion is one of the potential applications of this data. Lastly, video recordings are extremely difficult to structure for subsequent utilization; i.e., searching the video for specific information about a patient's condition would be extremely difficult, even using digital video.
What can be gained by using a digital motion capture technology?

There are direct and indirect gains to be made by using digital motion capture technology. Direct gains include the accuracy previously mentioned and its reuse for both quantitative and qualitative purposes. Indirect gains include an increased emphasis on motion as a principal component of depression as compared to emotion.

Quantitative reuse of the resulting digital data would allow for the potential "deconstruction" of the concept of psychomotor retardation. Velocity or acceleration of each body segment could be calculated, or a summation of the body could be determined. Angular velocity and acceleration could be calculated for each joint. This data, in total, would allow for much greater insight into what constitutes the most significant elements of psychomotor retardation. Biomechanical calculations could be made to better understand the relationship of depression with lower back pain, especially amongst those who do repetitive, physically taxing tasks such as lifting. ${ }^{55}$ Given the potential sensitivity and accuracy of the measures, they may prove of value in the characterization of chronic, severe refractory depressive disorders and in tracking treatment response, remission, and relapse.

Qualitative reuse of the digital data would allow for the development of avatars or virtual humans. These virtual humans could prove to be of value in educating the public about severe depressive illnesses. It has been asked, "How could virtual humans prove to be of greater value than videotapes of depressed patients?" First, one has to realize that there exist few videotapes of people with depression. Since few videos exist, one has to conclude that there is a reason. One speculation is that patients with these disorders do not want to be videotaped due to issues of confidentiality and privacy. It is here that virtual humans may prove to have enormous potential. A digital motion capture system could provide the movement constructs that would be used to animate a "virtual psychiatric patient." This virtual psychiatric patient would look and act like a depressed patient, yet the appearance of the 
patient could be altered so that it did not appear like the patient from whom the data originated. This would be accomplished by changing the digital appearance of the patient. The patient would be able to maintain privacy and confidentiality while sharing with the world the experience of having the illness. Such applications have not occurred yet, but it is only a matter of time before such applications occur.

The principal indirect gain of the use of digital motion capture technology is a shift from emotion to motion as the principal phenomenon of depression. Current diagnostic systems emphasize not only the primacy of the emotion of sadness, feeling blue, or being down, but they allow the subtyping of endogenous depression to be made based on the distinct quality of depression. There is no subtyping based on severity or degree of motion alteration. The Diagnostic and Statistical Manual, 4th ed. (DSMIV), Hamilton Depression Rating Scale, and the Zung Depression Rating Scale all have limited reference to alterations in motion. ${ }^{33-35}$ One of the most significant implications of motion being central in both representation and pathophysiology of depression is a need to study those factors whose alteration result in the illness. Given the primacy of emotion, most investigations and research of the last 20 years have focused on discovering the underlying neural mechanisms and systems responsible for the creation, modulation, and, potentially, the disruption of emotions. Norepinephrine and serotonin have been identified as the principal neurotransmitters responsible for depression, and many, if not most, of our psychopharmacology agents operate in such a way as to increase central levels of norepinephrine and serotonin.

Structural or neurotransmission pathway disruptions are two different conceptual models that might explain the pathophysiology of motion alterations seen in depression. Imaging studies of disorders with basal ganglia abnormalities show structural lesions, suggesting disruption of the circuits connecting basal ganglia to prefrontal and anterior cingulated cortex resulting in apathy, dystonia, and depression. ${ }^{56-58}$ Perfusion studies show reduced levels of cerebral blood flow in paralimbic regions, including the inferior frontal, anterior cingulated, and anterior temporal cortex. ${ }^{59-61}$ Despite most studies focusing on norepinephrine and serotonin, there are studies that support a dopamine component. These have demonstrated reductions of homovanillic (HVA) acid, a metabolite of dopamine in the cerebrospinal fluid of depressed patients. ${ }^{62-65} \mathrm{An}$ tidepressants that are dopamine agonists have been shown to be effective in those with depression, substantiating the potential role of dopamine. ${ }^{66-68}$ A number of genetic studies of depressed patients have shown an association with dopamine receptor genes. ${ }^{70,71}$

If motion could be better characterized, and if it served to identify a subtype of depression what might be the implications? Imaging studies could be developed that focused specifically on the dopamine areas of the brain such as the basal ganglia. Genetic studies could be developed to study dopamine transporter gene and its alteration in families in which depression appeared to be significantly represented. ${ }^{69}$ If motion were a consideration, how might we deal with the treatment of those with depression? Might we recommend physical rehabilitation rather than mental rehabilitation?

\section{CONCLUSION}

Digital motion capture technologies have promise, as compared to previous motion characterization technologies, which have been used to characterize psychomotor retardation in psychiatric research. Accuracy, stability, storage, and reuse make it superior to all other technologies used in this area before. Questions about its value appear to be based on a lack of knowledge concerning digital motion capture technologies in general and their use in other industries. With time, these technologies may prove to be valuable in the areas of research, clinical care, education, and communication about depression.

\section{REFERENCES}

1. Jackson, S.W. (1986). Melancholia and depression: from Hippocratictimes to modern times. New Haven, CT: Yale University Press. 
2. Evans, B. (1944). The psychiatry of Robert Burton. New York; Columbia University Press.

3. Kraepelin, E. (1921). Manic-depressiveinsanity and paranoia. Edinburgh: Livingstone.

4. Nelson, J.C., \& Charney, D.S. (1981). The symptoms of major depressive illness. The American Journal of Psychiatry, 138:1-13.

5. Parker, I.H.B.P. (1990). Prediction of response to electroconvulsive therapy. British Journal of Psychiatry, 157:65-71.

6. Rush, A.J., et al. (1994). Melancholic symptom features and DSM-IV. American Journal of Psychiatry, 151:489-498.

7. Re, K. (1968). The classification of depressive illness: Maudsley monograph 18. London: Oxford University Press.

8. Alexopoulos, G.S., et al. (1997). Clinically defined vascular depression. American Journal of Psychiatry, 154:562-565.

9. Bhrolchain, M.N., et al. (1979). Psychotic and neurotic depression: 2. Clinical characteristics. British Journal of Psychiatry, 134:94-107.

10. Kupfer, D.J., Weiss, B.L., Foster, G., Detre, T.P., Delgado, J., McPartland, R., \& Pittsburgh, M.E.E. (1974). Psychomotor activity in affective states. Archives of General Psychiatry, 30:765-768.

11. Wolff III, E.A., Putnam, F.W., \& Post, R.M. (1985). Motor activity and affective illness: the relationship of amplitude and temporal distribution to changes in affective state. Archives of General Psychiatry, 42:288-294.

12. Fleiss, J.L. (1972). Classification of the depressive disorders by numerical typology. Iournal of Psychiatric Research, 9:141-153.

13. Brandon, S., et al. (1984). Electroconvulsive therapy: results in depressive illness from the Leicestershire trial. British Medical Journal, 288:22-25.

14. Widlocher, M.D., \& Daniel, J. (1983). Psychomotor retardation: clinical, theoretical, and psychometric aspects. Psychiatric Clinics of North America, 6:27-40.

15. Hadzi-Pavlovic, G.P.D. (1993). Prediction of response to antidepressant medication by a sign-based index of melancholia. Australian and New Zealand Journal of Psychiatry, 27:56-61.

16. Parker, G., Hadzi-Pavlovic, D., Brodaty, H., Boyce, P., Mitchell, P., Wilhelm, K., Hickie, I., \& Eyers, K. (1993). Psychomotor disturbance in depression: defining the constructs. Journal of Affective Disorders, 27:255-265.

17. Parker, G., Hadzi-Pavlovic, D., Brodaty, H., Wilhelm, K., Hickie, I., Henry, Boyce, P., Mitchell, P., \& Eyers, K. (1994). Defining melancholia: properties of a refined sign-based measure. British Journal of Psychiatry, 164:316-326.

18. Parker, G., Hadzi-Pavlovic, D., Austin, M.-P., Mitchell, P., Wilhelm, K., Hickie, I., Boyce, P., \& Eyers, K. (1995). Sub-typing depression. I. Is psychomotor disturbance necessary and sufficient to the definition of melancholia? Psychological Medicine, 25:815-823.

19. Hickie, I., Mason, C., \& Parker, G. (1996). Comparative validity of two measures of psychomotor function in patients with severe depression. Iournal of Affective Disorders, 37:143-149.

20. Greden, J.F., Albala, A.A., Smokler, I.A., Gardner, R., \& Carroll, B.J. (1981). Speech pause time: a marker of psychomotor retardation among endogenous depressives. Biological Psychiatry, 16:851-859.

21. Flint, A.J., Black, S.E., Campbell-Taylor, I., Gailey, G.F., \& Levinton, C. (1993). Abnormal speech articulation, psychomotor retardation, and subcortical dysfunction in major depression. Lournal of Psychiat Research, 27:309-319.

22. Hoffmann, G.M.A., Gonze, J.C., \& Mendlewicz, J. (1985). Speech pause time as a method for the evaluation of psychomotor retardation in depressive illness. British Journal of Psychiatry, 146:535-538.

23. Kupfer, D.J., Detre, T.P., Foster, G., Tucker, G.J., \& Delgado, J. (1972). The application of Delgado's telemetric mobility recorder for human studies. Behavioral Biology, 7:585-590.

24. Post, R.M., Stoddard, F.J., Gillin, J.C., Buchsbaum, M.S., Runkle, D.C., Black, K.E., \& Bunney, Jr., W.E. (1977). Alterations in motor activity, sleep, and biochemistry in a cycling manic-depressive patient. Archives in General Psychiatry, 34:470-477.

25. Harms, U.G.A.K. (1985). A video analysis of the nonverbal behaviour of depressed patients before and after treatment. Affective Disorders, 9:63-67.

26. Sabbe, B., Hulstijn, W., Van Hoof, J., \& Zitman, F. (1996). Fine motor retardation and depression. Iournal of Psychiatric Research, 30:295-306.

27. Sloman, L., Berridge, M., Homatidis, S., Hunter, D., \& Duck, T. (1982). Gait patterns of depressed patients and normal subjects. American Journal of Psychiatry, 139:94-96.

28. Greden, J.F. (1993). Psychomotor monitoring: a promise being fulfilled? Journal of Psychiatric Research, 27:285-287.

29. Muybridge, E. (1901). The human figure in motion, an electro-photographic investigation of consecutive phases of muscular actions. London: Chapman \& Hall.

30. Chaffin, D.B., Martin, B.J., \& Andersson, G.B. (1999). Occupational biomechanics. New York: Wiley.

31. Frankel, V.K., et al. (1980). Basic biomechanics of the skeletal system. Philadelphia: Lea and Febiger.

32. Alessi, N.E., et al. (2000). Evolution of the virtual human: from term to potential application in psychiatry.

33. Thalmann, N.M., et al. (1994). Towards virtual humans in medicine: a prospective view. Computerized Medical Imaging and Graphics, 18:97-106.

34. Rush, A.J., et al. (2000). Depression and chronic low back pain: establishing priorities in treatment. Spine, 25:2566-2571.

35. Hamilton, M. (1960). A rating scale for depression. Journal of Neurology, Neurosurgery, and Psychiatry, 23:56-62.

36. Biggs, J.T., et al. (1978). Validity of the Zung Self-Rating Depression Scale. British Journal of Psychiatry, 132:381-385.

37. American Psychiatric Association. (1994). Diagnostic and statistical manual of mental disorders, 4th ed. (DSMIV). American Psychiatric Press.

38. Peyser, C.E., et al. (1990). Huntington's disease as a model for mood disorders. Clues from neuropathology and neurochemistry. Molecular Chemistry and Neuropathology, 12:99-119. 
39. Cummings, J.L. (1993). Frontal-subcortical circuits and human behavior. Archives of Neurology, 50:873-880.

40. Alexander, G.E., et al. (1986). Parallel organization of functionally segregated circuits linking basal ganglia and cortex. Annual Review of Neuroscience, 9:357-381.

41. Mayberg, H.S., et al. (1994). Paralimbic hypoperfusion in unipolar depression. Lournal of Nuclear Medicine, 35:929-934.

42. Bench, C.J., et al. (1993). Regional cerebral blood flow in depression measured by positron emission tomography: the relationship with clinical dimensions. $\underline{P s y-}$ chological Medicine, 23:579-590.

43. Dolan, R.J., et al. (1992). Regional cerebral blood flow abnormalities in depressed patients with cognitive impairment. Journal of Neurology, Neurosurgery, and Psychiatry, 55:768-773.

44. Brown AS, (1993). Dopamine and depression. Journal of Neural Transmission, 91:75-109.

45. Gjerris, A., et al. (1987). CSF dopamine increased in depression: CSF dopamine, noradrenaline and their metabolites in depressed patients and in controls. Journal of Affective Disorders, 13:279-286.

46. Reddy, P.L., et al. (1992). CSF amine metabolites in depression. Biological Psychiatry, 31:112-118.

47. Roy, A., et al. (1985). Cerebrospinal fluid monoamine and monoamine metabolite concentrations in melancholia. Psychiatry Research, 15:281-292.

48. Rudorfer, M.V., et al. (1984). Second-generation antidepressants. Psychiatric Clinics of North America, 7:519-534.

49. Rampello, L., et al. (1991). Dopaminergic hypothesis for retarded depression: a symptom profile for predicting therapeutical responses. Acta Psychiatrica Scandinavica, 84:552-554.

50. Goldstein, B.J., et al. (1984). Double-blind placebocontrolled multicenter evaluation of the efficacy and safety of nomifensine in depressed outpatients. Journal of Clinical Psychiatry, 45:52-55.

51. Laasonen-Balk, T., et al. (1999). Striatal dopamine transporter density in major depression. Psychopharmacology (Berlin), 144:282-285.

52. Manki, H., et al. (1996). Dopamine D2, D3 and D4 receptor and transporter gene polymorphisms and mood disorders. Lournal of Affect Disorders, 40:7-13.

53. Iversen, L. (2000). Neurotransmitter transporters: fruitful targets for CNS drug discovery. Molecular Psychiatry, 5:357-362.

54. Alessi, N.E. \& Huang, M.P. (2000). Evolution of the Virtual Human: From Term to Potential Application in Psychiatry.

55. Rush, A.J., Polatin, P., \& Gatchel R.J. (2000). Depression and chronic low back pain: establishing priorities in treatment. Spine, 25(20):2566-2571.

56. Alexander, G.E., DeLong, M.R., \& Strick, P.L. (1986). Parallel organization of functionally segregated circuits linking basal ganglia and cortex. Annual Review of Neuroscience, 9:357-381.

57. Cummings, J.L. (1993). Frontal-subcortical circuits and human behavior. Archives of Neurology, 50(8):873-880.

58. Peyser, C.E., \& Folstein, S.E. (1990). Huntington's disease as a model for mood disorders. Clues from neu- ropathology and neurochemistry. Molecular Chemistry Neuropathology, 12(2):99-119.

59. Dolan, R.J., Bench, C.J., Brown, R.G., et al. (1992). Regional cerebral blood flow abnormalities in depressed patients with cognitive impairment. Lournal of Neurology Neurosurgery and Psychiatry, 55(9):768-773.

60. Bench, C.J., Friston, K.J., Brown, R.G., et al. (1993). Regional cerebral blood flow in depression measured by positron emission tomography: the relationship with clinical dimensions. Psychology and Medicine, 23(3): 579-590.

61. Mayberg, H.S., Lewis, P.J., Regenold W., \& Wagner, H.N. Jr. (1994). "Paralimbic hypoperfusion in unipolar depression. Journal of Nuclear Medicine, 35(6):929-934.

62. Roy, A., Pickar, D., Linnoila, M., et al. (1985). Cerebrospinal fluid monoamine and monoamine metabolite concentrations in melancholia. Psychiatry Research, 15(4):281-292.

63. Reddy, P.L., Khanna, S., Subhash, M.N., et al. (1992). CSF amine metabolites in depression. Biology Psychiatry, 31(2):112-118.

64. Gjerris, A., Werdelin, L., Rafaelsen, O.J., et al. (1987). CSF dopamine increased in depression: CSF dopamine, noradrenaline and their metabolites in depressed patients and in controls. Lournal of Affective Disorders, 13(3):279-286.

65. Brown, A.S. (1993). Dopamine and depression. Lournal of Neural Transmissions, 91:75-109.

66. Goldstein, B.J., Brauzer, B., Kentsmith, D., et al. (1984). Double-blind placebo-controlled multicenter evaluation of the efficacy and safety of nomifensine in depressed outpatients. Iournal of Clinical Psychiatry, 45:52-55.

67. Rampello, L., Nicoletti, G., \& Raffaele, R. (1991). "Dopaminergic hypothesis for retarded depression: a symptom profile for predicting therapeutical responses. Acta Psychiatr Scand, 84(6):552-554.

68. Rudorfer, M.V., Golden R.N., \& Potter, W.Z. (1984). Second-generation antidepressants. Psychiatric Clinics of North America, 7(3):519-534.

69. Iversen, L. (2000). Neurotransmitter transporters: fruitful targets for CNS drug discovey. Molecular Psychiatry, 5(4):357-362.

70. Laasonen-Balk, T., Kuikka, J., Viinamaki, H., et al. (1999). Striatal dopamine transporter density in major depression. Psychopharmacology (Berl) 144(3):282-285.

71. Manki, H., Kanba, S., Muramatsu, T., et al. (1996). Dopamine D2, D3 and D4 receptor and transporter gene polymorphisms and mood disorders. Lournal of Affective Disorders, 40:7-13.

Address reprint requests to: Dr. Norman Alessi

Psychiatric Informatics Program Department of Psychiatry University of Michigan

1500 East Medical Center Drive Ann Arbor, MI 48109

E-mail: nalessi@umich.edu 